\title{
Сорбционная способность ультрафильтрационных мембран и потенциал поля поверхностных сил в растворах молочных белков
}

\author{
Богомолов В.Ю. ${ }^{1}$, Лазарев С.И. ${ }^{2}$, Полянский К.К. ${ }^{3}$, Стрельников А.Е. ${ }^{2}$ \\ ${ }^{1}$ ООО «ТМБ-Технологии», Котовск, Тамбовская обл. \\ ${ }^{2}$ ФГБОУ ВО «Тамбовский государственный технический университет», Тамбов \\ ${ }^{3}$ Воронежский филиал ФГБОУ ВО «Российский экономический университет имени Г.В. Плеханова», \\ Воронеж
}

Поступила в редакцию 6.10.2017 г.

В работе представлен анализ литературных данных по исследованию сорбционной способности мембран и потенциала поля поверхностных сил. Сформулирована цель работы и на основании литературного обзора выполнен выбор исследуемых ультрафильтрационных мембран УАМ-150 и УПМ-100. Методом переменных концентраций проведены экспериментальные исследования по сорбционной активности ультрафильтрационными мембранами белка из подсырной сыворотки. Получены численные значения равновесного коэффициента распределения белка в мембранах УАМ-150 и УПМ-100, и растворах молочной сыворотки в диапазоне изменения концентраций белка от 9 до 32 г/л при температурах от 293 до 308 К. Проанализировано влияние температуры и концентрации раствора молочного белка на сорбционную способность ультрафильтрационных мембран УАМ-150 и УПМ-100. На основании экспериментальных данных найдены численные значения эмпирических коэффициентов для теоретического расчета равновесного коэффициента распределения. Рассчитан потенциал поля поверхностных сил полупроницаемых мембран УАМ-150 и УПМ-100 и интерпретировано его изменение в зависимости от температуры и концентрации молочного белка.

Ключевые слова: ультрафильтрация, полупроницаемая мембрана, сорбционная способность, белок, потенциал поля поверхностных сил.

\section{The sorption capacity of ultrafiltration membranes and the potential field of the surface forces in solutions of milk proteins}

\author{
Bogomolov V.Y. ${ }^{1,2}$, Lazarev S.I. ${ }^{2}$, Polyansky K.K. ${ }^{3}$, Strelnikov A.E. \\ ${ }^{1}$ Ltd «TMB-Technologii», Kotovsk Tambov region \\ ${ }^{2}$ Tambov State Technical University, Tambov \\ ${ }^{3}$ Voronezh branch of the Plekhanov Russian University of Economics, Voronezh
}

The paper presents analysis of literature data to study the sorption capacity of the membranes and of the field potential of surface forces. Formulated the objectives based on the literature review, performed the selection of the studied ultrafiltration membranes UAM-150 UPM-100. The method of variable concentrations of experimental study of sorption activity of ultrafiltration membranes protein from cheese whey. The numerical values of equilibrium distribution coefficient of the protein in the membranes UAM-150 UPM100 , and solutions of milk whey in the range of protein concentrations from 9 to $32 \mathrm{~g} / \mathrm{l}$ at temperatures from 293 to $308 \mathrm{~K}$. based On the experimental data numerical values of empirical coefficients in the Freundlich equation for theoretical calculation of the equilibrium distribution coefficient. It is observed that the main factors influencing the sorption of substances by membranes from solution include the initial concentration in the solution and the temperature of the solution and analyzed the effect of temperature and concentration of 
the solution of milk protein on sorption capacity of ultrafiltration membranes UAM-150 UPM-100. In the case of increasing the temperature of the protein solution the sorption activity of membranes UAM-150 UPM-100 increased. The temperature increase reduces the viscosity and density of the solution and simultaneously increases its osmotic pressure. The decrease in the viscosity and density leads to increased permeability of the protein, increasing the concentration leads to saturation of the membranes with protein molecules, which further does not significantly increase the protein concentration in the membrane. The change in the concentration of solute at the membrane surface compared to its concentration in solution due to the influence of the field of surface forces. The calculated potential field of the surface forces of semi-permeable membranes UAM-150 UPM-100 and interpreted it change depending on the temperature and concentration of milk protein.

Keywords: ultrafiltration, semipermeable membrane, sorption capacity, protein, potential of the surface forces field.

\section{Введение}

До настоящего времени остаются дискуссионными вопросы переноса веществ через мембраны в процессах мембранного разделения растворов и в особенности растворов, содержащих органические вещества [1-5]. Существуют различные уравнения, описывающие перенос растворенных веществ через полупроницаемую мембрану, учитывающие вклад диффузии, осмотического давления и гелеобразования на мембранный процесс [6-7]. Следует отметить, что на проницаемость полимерных мембран оказывают влияние физико-химические свойства вещества, содержащегося в исследуемом растворе.

\section{Теоретическая часть}

В рассмотренных работах отмечается [1-7], что особое влияние на сорбционную способность оказывает физико-химические свойства вещества, контактирующего с мембраной. В большинстве случаев отмечается, что наиболее сильно изменяют свойства мембран сорбирующиеся на них органические вещества, в особенности белки и им подобные компоненты [8-13]. Величины гелеобразования, коэффициента диффузии и ряд других величин в уравнениях, описывающих массоперенос, определяются через равновесный коэффициент распределения растворенного вещества между растворителем и мембраной. Равновесный коэффициент распределения, в свою очередь, определяется по экспериментальным данным сорбционной емкости мембран или через расчет значений потенциала поля поверхностных сил - величины потенциала в пограничном слое, характеризующей диффузионные и сорбционные явления на границе раздела фаз и в поровом пространстве полупроницаемой мембраны [3-15].

Цель работы: исследование сорбционной способности ультрафильтрационных мембран УАМ-150 и УПМ-100 и потенциала поля поверхностных сил в растворах молочных белков.

\section{Эксперимент}

Исследования сорбционной способности мембран проводились методом переменных концентраций. В качестве объектов исследования использовались ультрафильтрационные мембраны УПМ-100 и УАМ-150 наиболее применяемые в промышленной практике, обладающие высокой задерживающей способностью и высокой производительностью. Характеристики исследуемых мембраны УПМ-100 и УАМ-150 представлены в таблице 1 [16]. В качестве раствора, использовались мо- 
дельные растворы подсырной сыворотки, получаемые при производстве сычужных сыров.

Таблица 1. Характеристики ультрафильтрационных мембран

\begin{tabular}{|c|c|c|c|c|c|c|}
\hline \multirow{3}{*}{$\begin{array}{c}\text { Наименование } \\
\text { мембраны }\end{array}$} & \multirow{3}{*}{$\begin{array}{c}\text { Материал } \\
\text { активного } \\
\text { слоя }\end{array}$} & \multirow{2}{*}{\multicolumn{2}{|c|}{$\begin{array}{c}\text { Производительность по } \\
\text { объемному потоку дис- } \\
\text { тиллированной воды } \\
\text { при трансмембранном } \\
\text { давлении }\end{array}$}} & \multicolumn{3}{|c|}{ Коэффициент задержания } \\
\hline & & & & \multirow[t]{2}{*}{$\begin{array}{c}\text { по } \\
\text { миоглобину }\end{array}$} & \multirow[t]{2}{*}{$\begin{array}{c}\text { по } \\
\text { альбумину }\end{array}$} & \multirow[t]{2}{*}{$\begin{array}{c}\text { по } \gamma \text { - гло- } \\
\text { булину }\end{array}$} \\
\hline & & МПа & $\mathrm{M}^{3} / \mathrm{M}^{2} \mathrm{c}$ & & & \\
\hline УПМ-100 & $\begin{array}{c}\text { полисуль- } \\
\text { фонамид } \\
\text { «Сульфон- } \\
4 \mathrm{T»}\end{array}$ & 0.10 & $2.78 \cdot 10^{-5}$ & 0.950 & 0.970 & 0.980 \\
\hline УАМ-150 & $\begin{array}{c}\text { ацетат целлю- } \\
\text { лозы }\end{array}$ & 0.15 & $4.11 \cdot 10^{-6}$ & 0.985 & 0.970 & 0.985 \\
\hline
\end{tabular}

Использовали образцы ультрафильтрационных мембран размером 60х150 мм. Толщину мембран измеряли микрометром. Образцы подготавливались обжатием под рабочим давлением в мембранной установке тупикового типа до получения постоянных значений производительности по дистиллированной воде. После подготовки толщина мембраны вновь измерялась микрометром. В стеклянных бюксах объемом $50 \cdot 10^{-6} \mathrm{~m}^{3}$ готовили растворы молочных белков различных концентраций: 9, 14, 28 и 32 г/л. В бюксы с растворами помещали подготовленные мембраны, после удаления с их поверхности излишков дистиллированной воды и плотно закрывали. Бюксы с образцами мембран помещали в термостат, выведенный на необходимый температурный режим, и выдерживали в нем в течение суток. После извлечения образцов мембран осуществляли повторный контроль их линейных размеров: длины, ширины и толщины. Затем, методом формольного титрования по ГОСТ 25179-90, измеряли концентрацию белковых растворов в бюксах и определяли разницу исходной и конечной концентраций. Далее рассчитывали равновесный коэффициент распределения, как отношение концентраций белков в мембране $\left(C_{M}\right)$ и в исходном растворе $\left(C_{1}\right)$ :

$$
k_{p}=C_{M} / C_{1} .
$$

По значениям равновесного коэффициента распределения $k_{p}$ рассчитывали значения потенциала поля поверхностных сил:

$$
U=-R T \ln \left(k_{p}\right),
$$

где $R$ - универсальная газовая постоянная; $T$ - температура в термостате с бюксами.

\section{Обсуждение результатов}

Основными факторами, влияющими на сорбцию веществ мембранами из растворов, являются исходная концентрация в растворе и температура раствора. Результаты экспериментальных исследований приведены на рис. 1 и 2 при различных температурах для растворов белков различной концентрации.

Для аналитического расчета равновесного коэффициента распределения в ультрафильтрационных мембранах использовали модифицированное уравнение Фрейндлиха следующего вида:

$$
k_{p}=\left(b \cdot C_{1}^{n} \cdot(293 / T)^{m}\right) / C_{1},
$$


где $b, n, m$ - эмпирические коэффициенты.

Значения эмпирических коэффициентов для аналитического расчета равновесного коэффициента распределения белка в мембранах приведены в таблице 2. Расхождение экспериментальных и расчетных значений не превышает $10 \%$. YAM-150

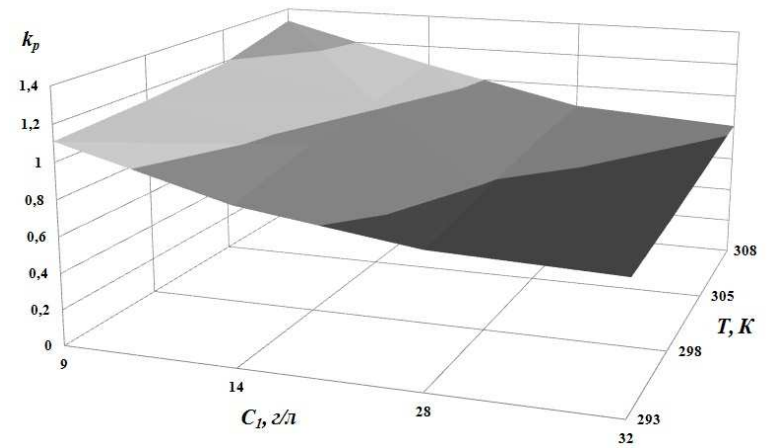

Рис. 1. Зависимость равновесного коэффициента распределения от концентрации белкового раствора и температуры для мембран УАМ-150

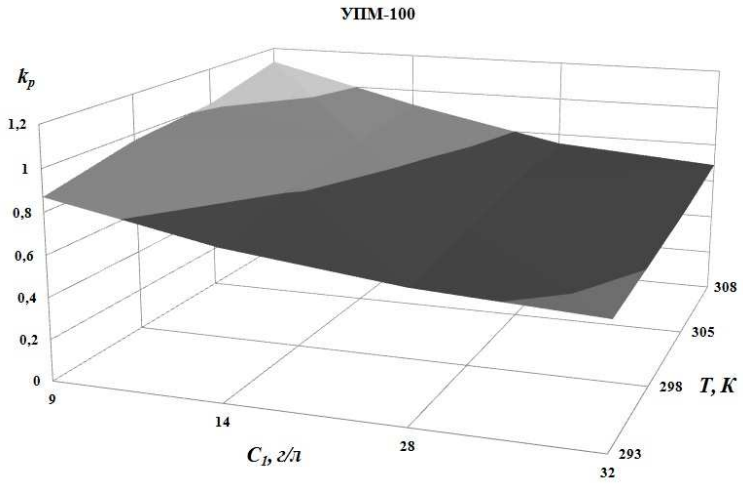

Рис. 2. Зависимость равновесного коэффициента распределения от концентрации белкового раствора и температуры для мембран УПМ-100

Таблица 2. Значения эмпирических коэффициентов уравнения (3) для расчета равновесного коэффициента распределения

\begin{tabular}{|c|c|c|c|}
\hline Мембрана & $\mathrm{b}$ & $\mathrm{n}$ & $\mathrm{m}$ \\
\hline УАМ-150 & 2.25564 & 0.65616 & -3.71567 \\
\hline УПМ-100 & 1.82953 & 0.66343 & -4.34813 \\
\hline
\end{tabular}

По данным экспериментальных исследований прослеживается, что с увеличением концентрации растворенного вещества в исходном растворе равновесный коэффициент распределения снижается. Это связано с насыщением мембран молекулами белков, после которого дальнейшие увеличение концентрации раствора не приводит к значительному увеличению концентрации в мембране. Высокая сорбционная активность мембраны УАМ-150 по сравнению с мембраной УПМ-100 обусловлена характером и величиной пор и аморфных областей в полимерных мембранах. Известно [7-8], что соотношение величины пор мембран с размером молекул растворенного вещества оказывает значительное влияние на сорбционную активность мембран. Неоднозначно и влияние температуры на сорбционную активность полупроницаемых мембран. В исследуемом случае с увеличением температуры белкового раствора сорбционная активность мембран УАМ-150 и УПМ-100 увеличивалась. Увеличение температуры уменьшает вязкость и плотность раствора и одновременно увеличивает его осмотическое давление. Уменьшение вязкости и плотности приводит к увеличению проницаемости белка, В условиях проводимого эксперимен- 
та мембраны помещались в бюксы с раствором без наложения на мембранную систему трансмембранного давления. Поэтому большое значение имел фактор увеличения проницаемости, вследствие чего большее количество молекул белков проницало в материал мембраны, тем самым увеличивая величину сорбционной активности.

Изменение концентрации растворенного вещества у поверхности мембраны по сравнению с его концентрацией в объеме раствора обусловлено влиянием поля поверхностных сил. Потенциал этого поля для полимерных мембран рассчитывается по уравнению (2) и, как и равновесный коэффициент распределения, зависит от концентрации растворенного вещества в растворе и от температуры раствора. Зависимости расчетных значений потенциала поля поверхностных сил мембран УАМ-150 и УПМ-100 от концентрации водного раствора молочного белка и температуры представлены на рис. 3 и 4.

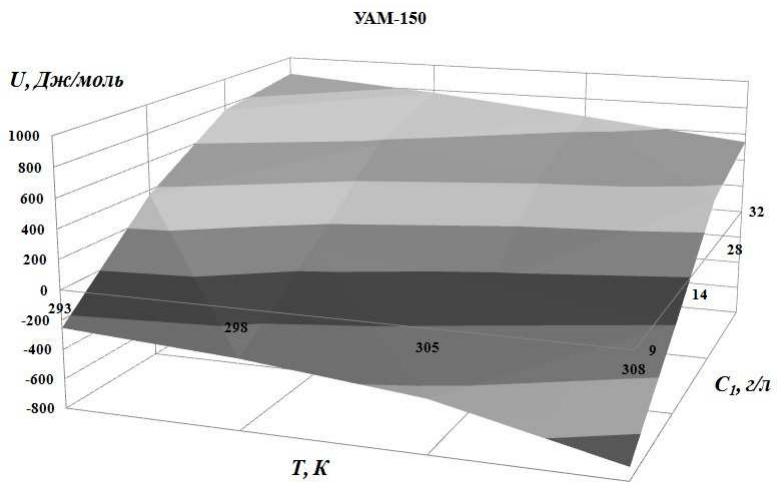

Рис. 3. Зависимость потенциала поля поверхностных сил от концентрации белкового раствора и температуры для мембран УАМ-150

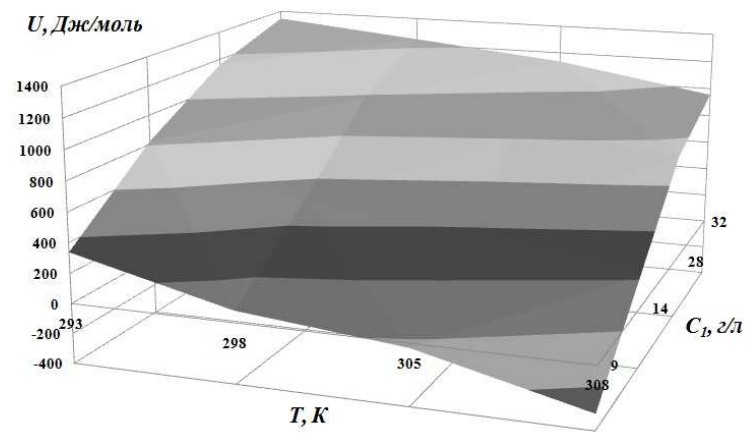

Рис. 4. Зависимость потенциала поля поверхностных сил от концентрации белкового раствора и температуры для мембран УПМ-100

С ростом концентрации растворенного белка в исходном растворе потенциал поля увеличивается, что объясняется ростом потенциальной энергии взаимодействия растворенного вещества со стенками пор мембраны. А увеличение температуры раствора приводит к снижению поверхностного потенциала. Вероятно, в случае белковых растворов, которые склонны к термолабильности, повышение температуры в системе мембрана-раствор изменяет кислотность и снижает вязкость раствора, как в порах мембраны, так и на пограничном слое, что снижает энергию взаимодействия белка с мембраной, это приводит к уменьшению потенциала поля поверхностных сил. На изменение потенциала поля поверхностных сил влияет количество функциональных групп, которые изменяют заряд мембраны и позволяют ей проявлять слабые ионные свойства. Для различных мембран эти явления проявляются в разной степени [14-15]. Так, из расчетных кривых видно, что потенциал поля поверхност- 
ных сил для полиамидных мембран УПМ-100 выше, чем для ацетатцеллюлозных мембран УАМ-150.

\section{Заключение}

Исследована сорбционная способность и получены данные по равновесному коэффициенту распределения белка в мембранах УПМ-100 и УАМ-150 в зависимости от концентрации и температуры подсырной сыворотки. Найдены численные значения коэффициентов в уравнении Фрейндлиха, что позволяет теоретически рассчитывать значения концентрации белка в ультрафильтрационной мембране. Рассчитан потенциал поля поверхностных сил, характеризующий сорбционные и диффузионные явления на границе раздела фаз и в поровом пространстве ультрафильтрационных мембран.

\section{Работа выполнена при финансовой поддержке со стороны Минобрнауки России в рамках базовой части государственного задания.}

\section{Список литературы}

1. Котов В.В., Перегончая О.В., Бодякина И.М. Электродиализ водных растворов, содержащих органические электролиты. Саарбрюккен. LAP 2014. 97 c.

2. Полянский К.К., Шапошник В.А., Пономарев А.Н. // Молочная промышленность. 2004. №10. C.48-49.

3. Мирончук В.Г., Грушевская И.О., Кучерук Д.Д., Змиевский Ю.Г. // Мембраны и мембранные технологии. 2013. Т. 3(1). С.3-8.

4. Храмцов А.Г., Нестеренко П.Г. Технология продуктов из молочной сыворотки М. ДеЛи принт. 2004. 587 с.

5. Лазарев В.А. Разделение и концентрирование молочной сыворотки на ультрафильтрационных и обратноосмотических мембранах: дисс. ... канд. техн. наук. М. РХТУ. 2015. $119 \mathrm{c}$.

6. Абоносимов О.А., Лазарев С.И., Абоносимов Д.О. //Сорбиионные и хроматографические процессы. 2013. Т. 13. № 2. С. 207212.

7. Чалых А.Е. Диффузия в полимерных системах. М. Химия. 1987. 312 с.

8. Технологические процессы с применением мембран. Пер. с анг. Л.А. Мазитова Т.М.
Мнацаканян. Под ред. Р.Е.Лейси и С. Лёба. М. Мир. 1979. 372 с.

9. Хорохорина И.В., Лазарев С.И. // Сорбиионные и хроматографические прочессы. 2016. T. 16. № 3. C. 361-367.

10. Пономарёв А.Н., Ключников А.И., Мерзликина А.А., Пронина О.В. и др. // Молочная промышленность. 2016. Вып. 4. С. 78-79.

11. Гаврилов Г.Б. // Техника и технология пищевых производств. 2009. № 1. С. 26-29.

12. Тимкин В. А., Гальчак И. П., Лазарев В.А., Минухин Л.А. // Экономика и экономические науки. 2013. Вып. 7 (113). С. 40-41.

13. Костюков Д.М., Куленко В.Г., Дыкало Н.Я., Костюков Е.М. и др. // Молочнохозяйственный вестник. 2012. № 1 (5). С.32-36.

14. Хорохорина И.В., Лазарев С.И. // Сорбиионные и хроматографические прочессы. 2016. T. 16. № 3. C. 361-367.

15. Головашин В.Л.,Ковалев С.В., Лазарев К.С., Чепеняк П.А.. // Сорбционные и хроматографические проиессы. 2010. Т. 10. № 2. C. 201-207.

16. Мембраны, фильтрующие элементы, мембранные технологии. Каталог. Владимир. ЗАО НТЦ Владипор. 2007. 22 с.

\section{References}

1. Kotov V.V., Peregonchaya O.V., rastvorov, soderzhashchikh organicheskie Bodyakina I.M., Elektrodializ vodnykh elektrolity, Saarbryukken, LAP, 2014, 97 c. 
2. Polyanskiy K.K., Shaposhnik V.A., Ponomarev A.N., Molochnaya promyshlennost', 2004, No 10, pp. 48-49.

3. Mironchuk V.G., Grushevskaya I.O., Kucheruk D.D., Zmievskiy Yu.G., Membrany $i$ membrannye tekhnologii, 2013, Vol. 3(1), pp. 3 8.

4. Khramtsov A.G., Nesterenko P.G. Tekhnologiya produktov iz molochnoy syvorotki, M, DeLi print, 2004, 587 p.

5. Lazarev V.A. Razdelenie i kontsentrirovanie molochnoy syvorotki na ul'trafil'tratsionnykh i obratnoosmoticheskikh membranakh: diss. ... kand. tekhn. Nauk, M, RKhTU, 2015, $119 \mathrm{p}$.

6. Abonosimov O.A., Lazarev S.I., Abonosimov D.O., Sorbtsionnye i khromatograficheskie protsessy, 2013, Vol. 13, No 2, pp. 207-212.

7. Chalykh A.E., Diffuziya v polimernykh sistemakh, M., Khimiya, 1987, 312 p.

8. Tekhnologicheskie protsessy s primeneniem membran. Per. $s$ ang. L.A. Mazitova T.M. Mnatsakanyan., Pod red. R.E.Leysi i S. Leba., M., Mir, 1979, 372 p.

Богомолов Владимир Юрьевич - к.т.н., генеральный директор ООО «ТМБ-Технологии», старший преподаватель каф. «Природопользование и защита окружающей среды», ТГТУ, Тамбов

Лазарев Сергей Иванович - д.т.н., профессор, зав. каф. «Прикладная геометрия и компьютерная графика», ТГТУ, Тамбов

Полянский Константин Константинович д.т.Н., профессор, Воронежский филиал Российского экономического университета имени Г.В. Плеханова, Воронеж

Стрельников Александр Евгеньевич - аспирант, каф. «Прикладная геометрия и компьютерная графика», ТГТУ, Тамбов
9. Khorokhorina I.V., Lazarev S.I. Sorbtsionnye i khromatograficheskie protsess,. 2016, Vol. 16, No 3, pp. 361-367.

10. Ponomarev A.N., Klyuchnikov A.I., Merzlikina A.A., Pronina O.V. et al., Molochnaya promyshlennost', 2016, No 4, pp. 78-79.

11. Gavrilov G.B., Tekhnika i tekhnologiya pishchevykh proizvodstv, 2009, No 1, pp. 26-29.

12. Timkin V. A., Gal'chak I. P., Lazarev V. A., Minukhin L. A., Ekonomika i ekonomicheskie nauki, 2013, Vyp. 7 (113), pp. 40-41.

13. Kostyukov D.M., Kulenko V.G., Dykalo N.Ya., Kostyukov E.M. et al., Molochnokhozyaystvennyy vestnik, 2012, No 1 (5), pp.32-36.

14. Khorokhorina I.V., Lazarev S.I., Sorbtsionnye i khromatograficheskie protsessy, 2016, Vol. 16, No 3, pp. 361-367.

15. Golovashin V.L. i dr., Sorbtsionnye $i$ khromatograficheskie protsessy, 2010, Vol. 10, No 2, pp. 201-207.

16. Membrany, fil'truyushchie elementy, membrannye tekhnologii, Katalog, Vladimir, ZAO NTTs Vladipor, 2007, 22 p.

Bogomolov Vladimir Y. - Can. Eng. Sci., head ltd «TMB-Technologii», lecturer of Tambov State Technical University, Tambov, e-mail: geometry@mail.nnn.tstu.ru

Lazarev Sergey I. - Dr.Sci.Tech., the professor of Tambov State Technical University, Tambov, email: geometry@mail.nnn.tstu.ru

Polyansky Konstantin K. - Dr.Sci.Tech., the professor of Voronezh branch of the Russian University of Economics named after G.V. Plekhanov, Voronezh, e-mail: tovar201@ list.ru

Strelnikov Alexander E. - postgraduate student, of Tambov State Technical University, Tambov, email: geometry@mail.nnn.tstu.ru 